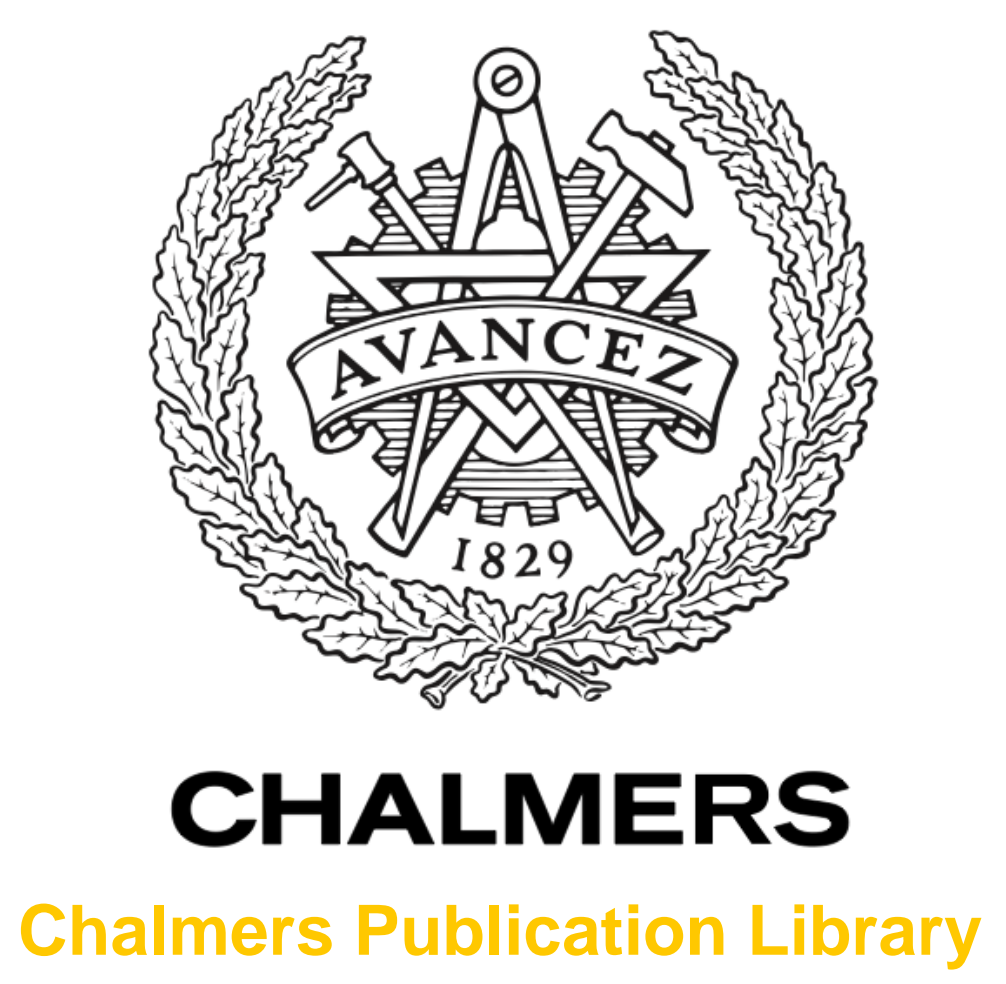

Development of the cryogenic 2-14 GHz eleven feed system for VLBI2010

This document has been downloaded from Chalmers Publication Library (CPL). It is the author's version of a work that was accepted for publication in:

Proceedings of 6th European Conference on Antennas and Propagation, EuCAP 2012. Prague, 26-30 March 2012

Citation for the published paper:

Yang, J. ; Pantaleev, M. ; Ekebrand, T. (2012) "Development of the cryogenic 2-14 GHz eleven feed system for VLBI2010". Proceedings of 6th European Conference on Antennas and Propagation, EuCAP 2012. Prague, 26-30 March 2012 pp. 621-625.

http://dx.doi.org/10.1109/EuCAP.2012.6206604

Downloaded from: http://publications.lib.chalmers.se/publication/156676

Notice: Changes introduced as a result of publishing processes such as copy-editing and formatting may not be reflected in this document. For a definitive version of this work, please refer to the published source. Please note that access to the published version might require a subscription.

Chalmers Publication Library (CPL) offers the possibility of retrieving research publications produced at Chalmers University of Technology. It covers all types of publications: articles, dissertations, licentiate theses, masters theses, conference papers, reports etc. Since 2006 it is the official tool for Chalmers official publication statistics. To ensure that Chalmers research results are disseminated as widely as possible, an Open Access Policy has been adopted.

The CPL service is administrated and maintained by Chalmers Library. 


\section{Development of the Cryogenic 2-14 GHz Eleven Feed System for VLBI2010}

\author{
Jian Yang, Per-Simon Kildal, Hasan Raza \\ Dept. of Signals and Systems, Chalmers University of \\ Technology, Sweden
}

\author{
Jungang Yin \\ Dept. of Electronics and \\ Telecommunications, Norwegian \\ University of Science and \\ Technology, Norway
}

\author{
Miroslav Pantaleev, Leif Helldner \\ Onsala Space Observatory, Chalmers University of \\ Technology, Sweden
}

\author{
Terese Ekebrand, Jan Jönsson, \\ Anders Emrich \\ Omnisys Instruments AB, Sweden
}

\author{
Benjamin Klein \\ Hartebeeshoek Radio Astronomy \\ Observatory, Krugersdorp 1740, \\ South Africa
}

\begin{abstract}
We present an overview of the recent developments of a cryogenic 2-14 GHz feed system for the Very Long Baseline Interferometry 2010 (VLBL2010) project.
\end{abstract}

\section{INTRODUCTION}

High-precision geodesy is central to a broad variety of human activities, including private, commercial and governmental interests, as well as being of broad scientific interest. Very Long Baseline Interferometry (VLBI) is one of the three major modern geodesy space-based observing systems. With the importance of high accuracy geodesy to science and society, the new generation of VLBI system, VLBI2010 [1], is aiming to the following goals: 1) $1 \mathrm{~mm}$ measurement accuracy on global baselines; 2) continuous measurements for time series of station positions and Earth orientation parameters; 3) turnaround time to initial geodetic results of less than 24 hours; 4) a broad, continuous frequency range $(2-14 \mathrm{GHz})$ observation.

Wideband feed system for reflector antennas is one of the major challenges in the project. The feed must be compact in size so that it can be located inside a cryostat in order to be cryogenically cooled for a minimum system noise temperature. The phase center location of the feed must be constant over the frequency band in order to achieve the 1-mm measurement accuracy. In addition, constant beam width, high aperture efficiency, low cross-polar level, and low input reflection coefficient, over the whole wideband, are also very important for the system.

Among all modern wideband feed technologies, the Eleven feed is a unique one which can fulfill all requirements of the VLBI project. The Eleven feed is a cascaded log-periodic folded dipole array, having a nearly constant beamwidth with $11 \mathrm{dBi}$ directivity, a fixed phase center location, and a simple geometry with a low profile.

This paper summarizes the recent developments on the Eleven feed technology for VLBI2010. This includes the design and testing of the 8-port version in [2], a way of making it more compact by bending down the outer dipoles, the circular eleven feed to improve high frequency performance, and the development of a wideband balun in order to reduce the number of ports to four, as well as modeling of system noise temperature, integration of different types of LNAs (differential or single-ended), and packaging of everything in a cryostat. The eleven antenna system with LNAs in cryostat is provided commercially by Omnisys Instruments $\mathrm{AB}$ for VLBI2010.

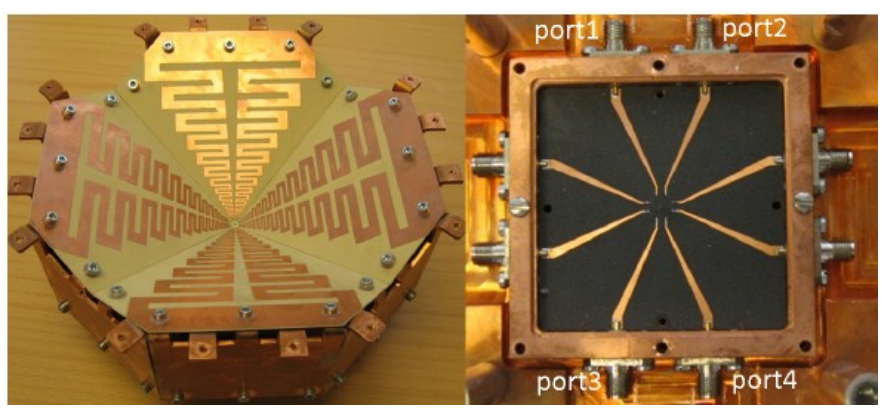

Figure 1: The existing 2-13 GHz Eleven feed

\section{FEED DEVELOPMENT}

Figure 1 shows picture of the existing $2-13 \mathrm{GHz}$ Eleven feed [2]. The further developments of the feed include: 1) the new balun feeding network, see Figure 2 (right) and the prototype in Figure $3 ; 2$ ) the new circular Eleven feed which improves the BOR1 efficiency over a decade bandwidth, see Figure 2. Figure 4 shows the simulated aperture efficiency and its subefficiencies. From this, we see that the aperture efficiency is above $-2.5 \mathrm{~dB}$ over the whole band of 2-14 GHz, and even down to $1 \mathrm{GHz}$.

\section{System ANALYSIS AND TeST}

The system analysis includes the development of noise model to characterize the expected receiver and system noise performance and analysis of the effect of the infrared filters and vacuum window when the feed is integrated in cryostat. 


\section{RECEIVE INTEGRATION}

The receiver integration includes the design, fabrication and tests of cryogenic receiver including Eleven feed, low noise amplifiers (LNAs), temperature stabilization and feeding network to realize circular polarization. The validation and selection of different LNA alternatives will be discussed from performance, operation and reliability point of view. The measured receiver temperature with wideband $50 \mathrm{ohm}$ LNAs is about $20 \mathrm{~K}$ over $70 \%$ of the $2-14 \mathrm{GHz}$ band.

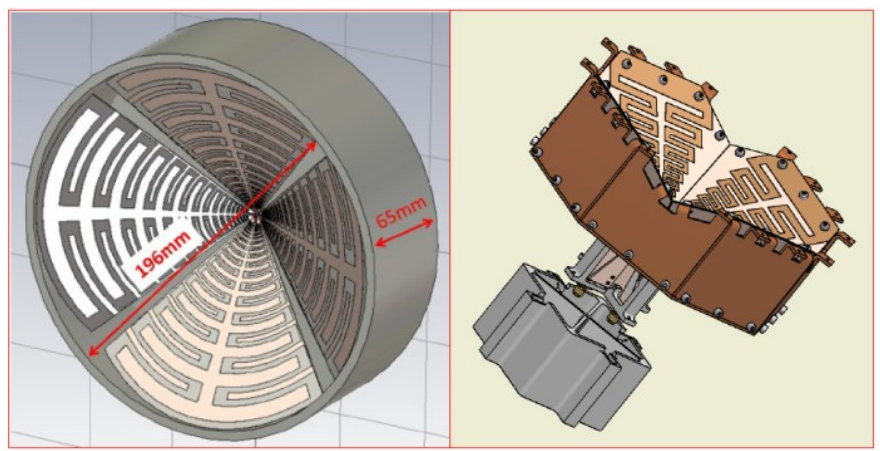

Figure 2: 1.3-14 GHz new circular Eleven feed (left) and new balun solution (right)

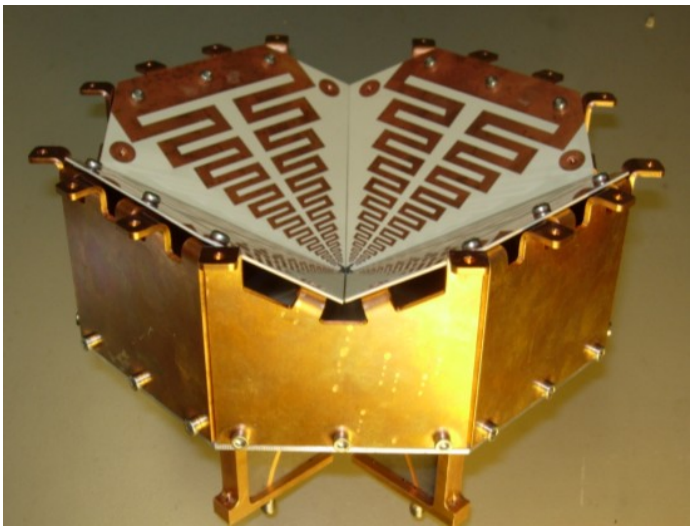

Figure 3 The prototype of the Eleven feed with the balun feeding

\section{CONCLUSION}

In the full paper, we will present the measurement data for the feed performance, the analysis of the effect on the feed efficiency by the dielectric material based on the simulations and the measurements, optimization of the vacuum window diameter to achieve optimal performance, and the receiver noise test data of the Eleven feed integrated with cryogenic LNAs.

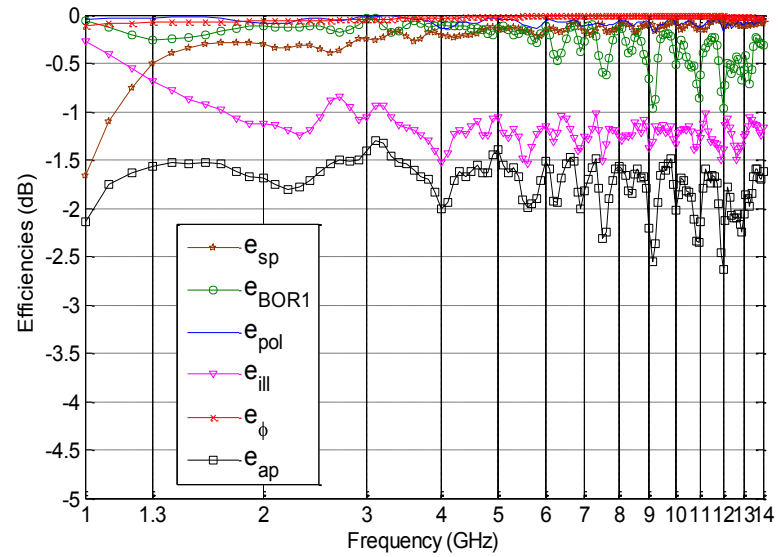

Figure 4 Simulated aperture efficiency and its sub-efficiencies

\section{REFERENCES}

[1] Niell, A., A. Whitney, W. Petrachenko, W. Schlüter, N.Vandenberg, H. Hase, Y. Koyama, C. Ma, H. Schuh, G. Tuccari, "(2005) VLBI2010: Current and Future Requirements for Geodetic VLBI Systems," IVS WG3 Report, http://ivscc.gsfc.nasa.gov/about/wg/wg3.

[2] J. Yang, M. Pantaleev, P.-S. Kildal, B. Klein, Y. Karandikar, L. Helldner, N.Wadefalk,C. Beaudoin "Cryogenic 2-13 GHz Eleven feed for reflector antennas in future wideband radio telescopes", IEEE Trans. on Antennas Propag., vol. 59, no. 6, pp. 1918-1934, June 2011. 